\title{
OS SISTEMAS DE INFORMAÇÃO COMO DETERMINANTES NA USABILIDADE DE PRODUTOS \\ Análise do Secador Taiff Gloss
}

Layanna Roberta Madeiro Lobo de Castro

Thallysson Henrique de Melo Oliveira

Maria Eduarda Ramos Cavalcanti Rosa

Resumo: Os sistemas de informação transmitem mensagens, recebidas através dos canais sensoriais - visão, tato, audição - que auxiliam o usuário na tomada de decisões e na interação com o produto. 0 emprego correto desses dispositivos promove a usabilidade, garantindo conforto e segurança, enquanto o contrário pode gerar erros e até acidentes. Dada a importância do tema e oportunidade de aplica-lo ao design de produto, examinou-se o um objeto de uso cotidiano, o secador Gloss, da marca Taiff, evidenciando o uso de seus sistemas. O diagnóstico obtido, indicou, dentre outros fatores, o comprometimento da usabilidade e da vida útil do produto, e permitiu a elaboração de diretrizes para melhorias dos quesitos falhos.

Palavras-chave: design de produto, ergonomia cognitiva, sistemas de informação, usabilidade.

\section{INTRODUC̣ÃO}

Entende-se como sistema ou dispositivo da informação o conjunto de instrumentos responsáveis pela transmissão de informações sobre a máquina, dispositivo, produto, ambiente ou sistema ao homem, para que este possa tomar decisões. De acordo com lida (2005):

\begin{abstract}
"O ser humano é dotado de muitos tipos de células sensíveis, mas principalmente a visão e audição são importantes no contexto do trabalho e, portanto, são mais estudadas pela ergonomia. A visão, em particular, se destaca como o principal órgão para recepção de informações no trabalho" (IIDA, 2005, p. 287).
\end{abstract}

São os nossos sentidos responsáveis pela absorção de tudo que acontece ao nosso redor, enquanto a interpretação ocorre através da percepção, que é o "produto dos processos psicológicos nos quais: significado, relações, contexto, julgamento, experiência passada e memória desempenham um papel importante" (SHIFFMAN, 2005).

É possível designar o estudo dos sistemas de informação, portanto, à área da ergonomia cognitiva, que segundo a Associação Brasileira de Ergonomia (ABERGO), "refere-se aos processos mentais, tais como percepção, memória, raciocínio e resposta motora conforme afetem as interações entre seres humanos e outros elementos de um sistema.".

Consoante a Gomes Filho (2006) são os exemplos de sistemas da informação: mostradores (relógios, voltímetros, termômetros), sistemas de orientação (placas de

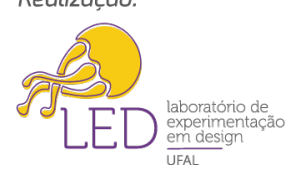


sinalização), chaves, botões, alavancas, etc. Eles correspondem ao "conhecimento e à descrição dos diversos tipos de informação inscrita e transmitida por determinados produtos, com as quais o usuário dialoga, atua e interage antes e durante o processo de uso". lida (2005) ressalta que eles "estão presentes em muitos tipos de produtos, ambientes e situações", chegando "até painéis de controle complexos, como cabinas de aeronaves e centrais de controle de uma usina nuclear. Um projeto inadequado de tais instrumentos pode causar erros, demoras e acidentes".

Nesse sentindo, é crucial que se projete visando à ergonomia, pois além de garantir segurança, proporciona e o correto desempenho e uso de produtos, inclusive do cotidiano da maioria das pessoas, como destacado por Dul e Weerdmeester (2004) "um exemplo bem conhecido é o do fogão doméstico, que leva a frequentes erros, devido ao relacionamento ambíguo entre os botões e os queimadores.".

Além disso, é extremamente necessário ao desenvolver um dispositivo informacional considerar o público e suas respectivas características: idade, sexo, escolaridade, nacionalidade, cultura, etc., afinal são todos determinantes do modo como o sistema será possivelmente interpretado, quais as limitações ao cria-lo, e o mais importante como adequá-lo aos usuários. Um sistema que contém informações escritas com letras muito pequenas, ou baixo contraste, por exemplo, dificulta seu uso por um público mais idoso.

Essas são medidas imprescindíveis para torna-lo acessível e compreensível, garantindo a usabilidade, isto é: "medida na qual um produto pode ser usado por usuários específicos para alcançar objetivos específicos com eficácia, eficiência e satisfação em um contexto específico de uso" (Associação Brasileira de Normas Técnicas, 2002).

Devem-se considerar ainda requisitos como a possibilidade de: feedback do sistema (cada ação realizada gera um retorno, mostrando que funciona, ou não), de controle (por exemplo, a velocidade com que ocorre uma operação), de tolerância de erro (possível corrigir, voltar), e de adaptabilidade e aprendizagem (se for necessário, prover auxilio para compreensão do programa).

O esquema da figura 1 demonstra a conexão entre os requisitos de um sistema de informação e a usabilidade, de modo que ela se relacionada não só com quem se interage (usuário), como também com o equipamento e o meio em que está inserido (ambiente), e é atingida com o cumprimento dos objetivos estipulados previamente, obtendo, portanto certa eficácia.

Dependendo do nível de eficácia alcançada, há uma diferente eficiência, que está relacionada ao gasto de recursos: esforço mental ou físico, tempo, custos materiais ou financeiros. A satisfação mede a extensão pela qual os usuários estão livres de desconforto e suas atitudes em relação ao uso do produto. 
Figura 1 - Estrutura da Usabilidade. Fonte: Associação Brasileira de Normas Técnicas (2002).

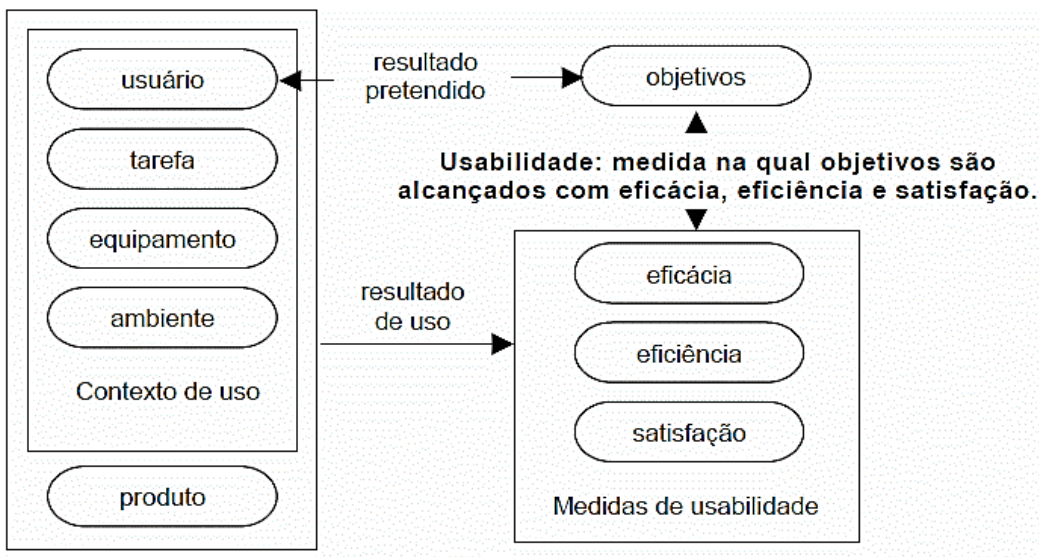

Figura 1 - Estrutura de usabilidade

Um dos sistemas de informação visual mais presentes no cotidiano são as representações pictóricas estáticas, dispostas em gráficos, sinalizações, cartazes, como no exemplo da figura 2. Eles são representações de objetos e conceitos traduzidos em uma forma gráfica e simplificada, recorrendo ao caráter simbólico da linguagem, relacionado à esfera semiótica, que através dos signos, consegue estabelecer relação entre outros signos, os seus significados e os seus intérpretes, os usuários.

Figura 2 - Pictogramas de acessibilidade. Fonte: Adaptado de www.sinestesiaurbana.wordpress.com (2011).
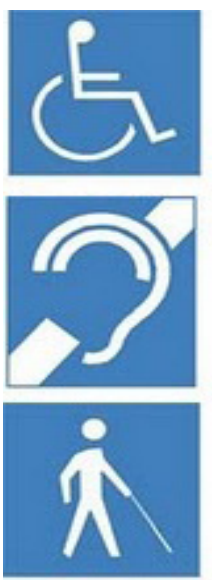

a) Branco sobre fundo azul
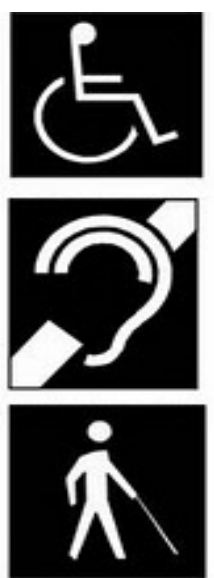

b) Branco sobre fundo preto
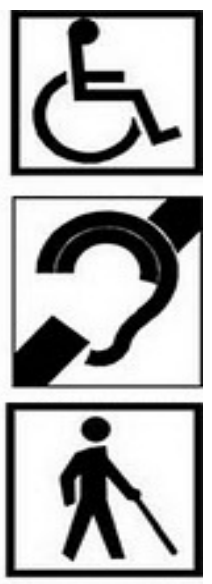

c) Preto sobre fundo branco

O uso de determinados signos pode estar muitas vezes relacionado aos estereótipos populares, que correspondem ao modo de organização ou uso ao que a maioria dos usuários está condicionada. Para lida (2005), "a principal vantagem dos símbolos decorre da proximidade maior com o objeto real que representam que pode mudar de acordo com o nível de abstração da imagem, bem como o grau de instrução do usuário, cultura, faixa etária”.

A adoção de pictogramas é um dos exemplos de como os sistemas informacionais recorrem à aplicação dos "conceitos ergonômicos e gestálticos que concorrem para a adequada pregnância da forma em termos de legibilidade, descriminabilidade correta, interpretação e compreensão das mensagens difundidas (...)" (GOMES FILHO, 2006).

A pregnância da forma se trata da Lei Básica da Percepção Visual da Gestalt, que define que "quanto melhor for a organização visual da forma do objeto, em termos de facilidade de compreensão e rapidez de leitura e interpretação, maior será o seu grau de pregnância" (GOMES FILHO, 2004). 
Uma das formas de se atingi-la, por exemplo, é o uso de outro princípio da Gestalt, a segregação, "capacidade perceptiva de separar, identificar, evidenciar ou destacar unidades formais em um todo compositivo ou partes deste todo" (GOMES FILHO, 2004). Isso pode se dar pela discrepância entre cores, texturas, brilhos e sombras, dentre outros.

Além dos sistemas de informação visual, também são encontrados sistemas que utilizam outros sentidos, de acordo com Gomes Filho (2006) como, por exemplo: a) audição: transmitindo informação por meios de sinais sonoros, com o fim de chamar a atenção ou aguçar esse sentido, por meio de ruídos, bips, buzinas; b) tato: transmite informação por sensações de contato, como pressão, vibração e térmica.

Devido a empecilhos que tornam a tarefa cansativa, como excesso de texto, baixa leiturabilidade, falta de objetividade, é comum que os usuários só recorram aos manuais de instrução, em caso de extrema necessidade, o que torna necessário que os sistemas da informação sejam cada vez mais autossuficientes em sua capacidade de transmitir o conhecimento requisitado para o funcionamento do respectivo objeto.

Dessa forma, o estudo do tema é importante na garantia o bom uso e segurança da população, que diariamente entra em contato com diversos objetos, softwares e ambientes. Além disso, a ABERGO (2000) evidencia que "a aplicação da Ergonomia, enquanto uma abordagem interdisciplinar no âmbito da atividade do trabalho é essencial para a produção de produtos mais competitivos e amigáveis e para a melhoria da produtividade organizacional." Diante disso, o presente trabalho tem como objetivo examinar um produto quanto aos seus sistemas da informação, ressaltando a forma como foram desenvolvidos, propondo melhoras quando necessário.

\section{DESENVOLVIMENTO}

\subsection{Estudo de caso}

Como objeto de estudo, escolheu-se o secador de cabelos da marca Taiff, modelo Gloss, exposto na figura 3. O produto é destinado tanto ao uso doméstico pessoal, quanto também para o uso por profissionais, como os de salões de beleza.

Figura 3 - Secador Taiff Gloss. Fonte: www.megasoares.com.br (2017).

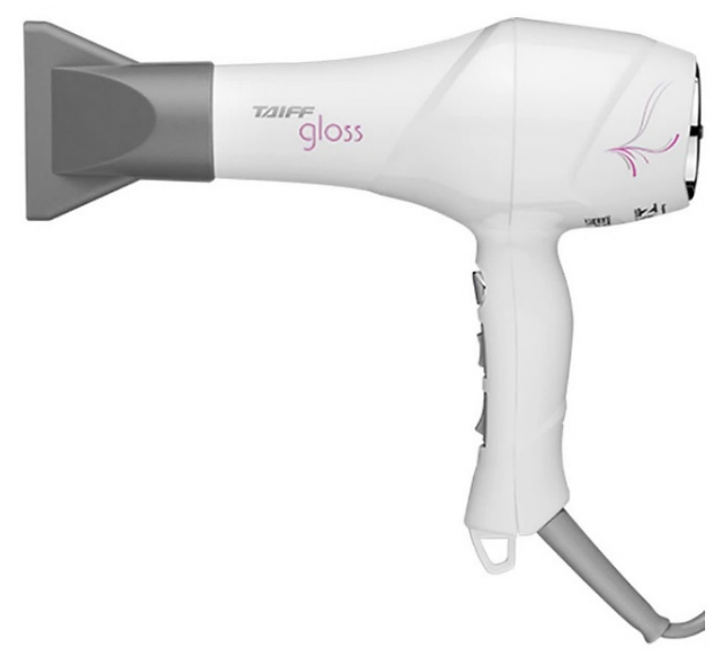

Ele apresenta cinco sistemas de informação principais, sendo tratados neste trabalho como sistema 1, sistema 2, sistema 3, sistema 4 e sistema 5. 


\subsubsection{Sistema 1 - Botões}

O primeiro sistema possui três componentes, como expostos na figura abaixo. 0 botão 1 contém um pictograma estático, associado à sensação de frio ou gelo, e ele aciona a função do jato de ar frio. Além disso, é adotado um formato diferenciado dos demais, o arredondado, tornando discriminável e evitando a confusão entre outras funções. Também é usada a cor azul no pictograma, o que remete à função, devido ao fato de ser uma cor fria, apelando para o senso comum do usuário como um fator de distinção da sua finalidade.

Figura 4 - Botões do sistema 1. Fonte: Adaptado de www.casasbahia-imagens.com.br (2017).

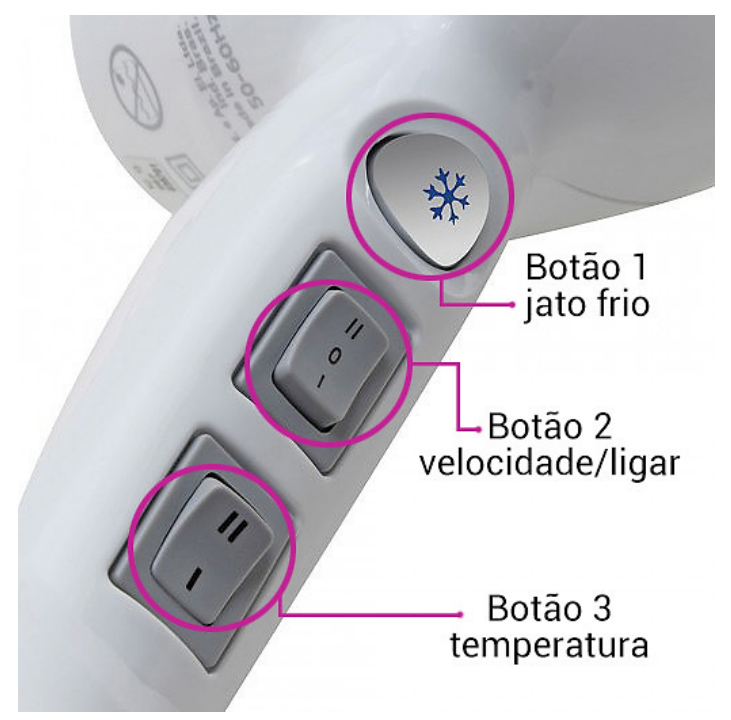

Do ponto de vista de pegas e manejos, ao utilizar o produto é feita uma apreensão palmar com toda a mão (figura 5), já que se trata de um objeto pesado e relativamente volumoso.

Figura 5 - Exemplo de preensão palmar com toda a mão. Fonte: Adaptado de www.ssglobal.com.br (2017).

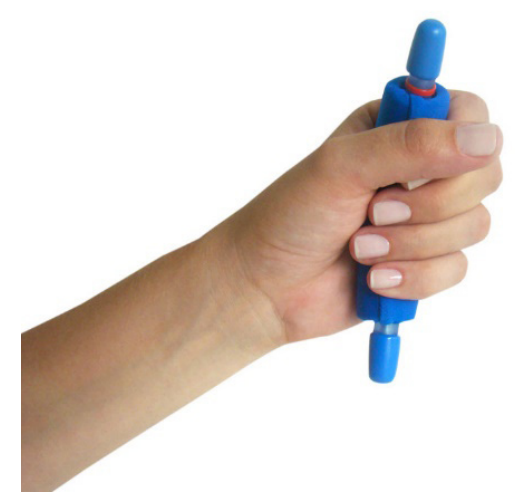

Porém ao utilizar esse botão em específico, é necessário que o indicador acione o botão constantemente durante toda a tarefa (figura 6) para que o fluxo de ar continue frio. Isso gera fadiga, o que é desconfortável para o usuário, que além do manejo grosseiro (movimento dos membros) terá que realizar concomitantemente manejo fino (pressão com o dedo). Caso contrário, pressionar somente uma vez fará com que o jato volte ao modo convencional, quente. 
Figura 6 - Uso do botão de jato frio. Fonte: Elaborado pelo autor, com base na pesquisa realizada (2017).

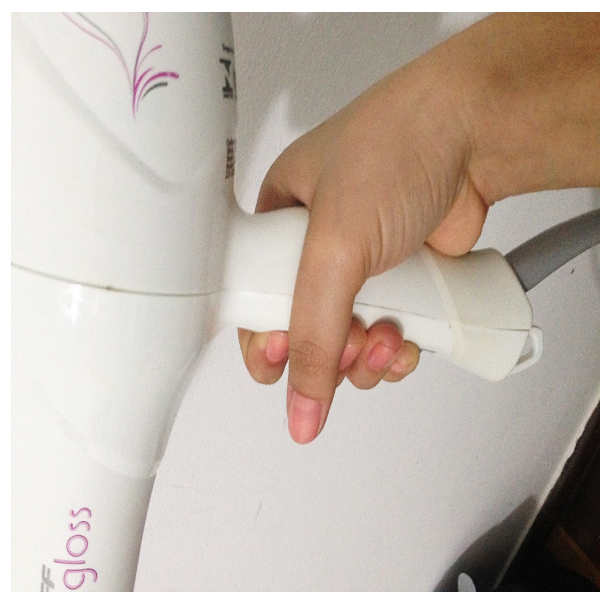

0 botão 2 se trata de uma chave gangorra com 3 posições, referentes à velocidade, designadas no sistema por I, 0 e II (figura 4), sendo respectivamente, a menor velocidade, posição neutra (produto desligado) e a maior velocidade. O botão se diferencia do de jato frio pelo formato, cor e acabamento e pela linguagem utilizada, sendo de algarismos romanos, contrária à do botão 1, que usa um pictograma. A única diferenciação do botão 3 é a ausência da posição 0 na chave, gerando uma dificuldade na distinção entre os dois. Acionar esse botão tanto na chave I, quanto na II, faz com que ele ligue independentemente da posição que o botão 3 se encontre. Assim que se consegue liga-lo, compreende-se, por dedução, que o outro botão é correspondente à temperatura.

Esse sistema causa muita confusão ao usuário, que precisa estar disposto a aprender esse funcionamento quase todas as vezes que usa, quando o uso do produto é esporádico, como no uso doméstico, ou acabar se condicionando pelo uso constante, como o dos profissionais. Isso está relacionado com a capacidade do ser humano de armazenar informações em curto prazo e em longo prazo. lida (2005) comenta que:

\footnotetext{
"a memória de curta duração (MCD), também chamada de memória de trabalho ou de curto prazo, retém as informações por períodos extremamente curtos, de 5 a 30 segundos, ao cabo dos quais, são completamente esquecidas, na maior parte das vezes" (IIDA, 2005, p. 260).
}

Ainda de acordo com o autor, a memória de longa duração, por sua vez "tem caráter associativo. As novas informações são mais bem fixadas quando se conectam com a rede neural já existente no cérebro", o que justifica, por exemplo, o uso conjunto de sistemas da informação: um supre a deficiência do outro na transmissão da mensagem, ajudando na interpretação e memorização.

O ideal nesse caso seria um sistema auxiliar que faça a distinção, ou que os próprios sistemas fossem projetados de forma mais clara e discriminável entre si, como sugerem Dul e Weerdmeester (2004):

"Os controles devem ter formas diferenciadas, para que não sejam confundidos com outros, mesmo sem o acompanhamento visual. Eles podem ser também diferenciados no material e rugosidade, para serem identificados por tato. 0 acionamento errado de controles pode provocar acidente, levando a sérias consequências" (DULE WEERDMEESTER, 2004, p. 51).

\subsubsection{Sistema 2 - Certificados e avisos de segurança}

$\mathrm{Na}$ figura que segue, percebe-se a utilização de pictogramas a fim de enfatizar cuidados e certificações do produto. O primeiro no canto superior esquerdo, trata-se da certificação do INMETRO - Instituto Nacional de Metrologia, Qualidade e Tecnologia presente no produto, e a certificação de produtos através do OCP P0005 - Organismo de 
Certificação de Produtos - órgão do INMETRO responsável pela certificação de qualidade do produto.

Fiqura 7 - Pintura escrita e pictoqramas. Fonte: Elaborado pelo autor, com base na pesquisa realizada (2017).

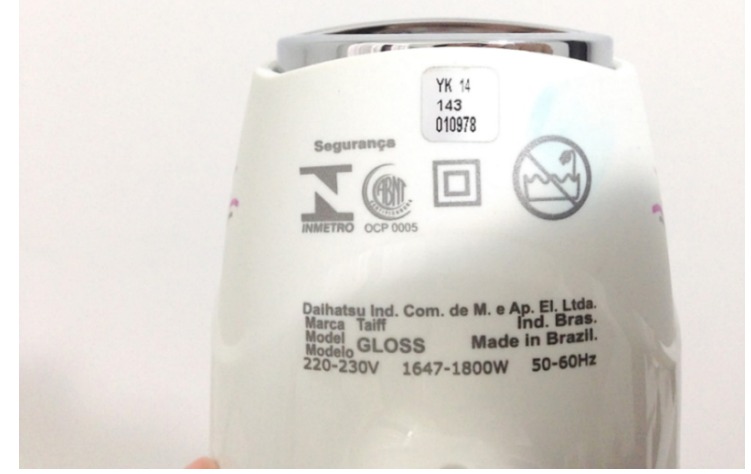

No canto superior direito são encontrados pictogramas referentes a cuidados com o produto, estes são muitas vezes ignorados pelos usuários devido à falta de repertório para interpretação dos mesmos, porém são de extrema importância como mostra a figura 8 abaixo.

Figura 8 - Pictogramas de cuidados. Fonte: Manual do Secador GLOSS (2017)

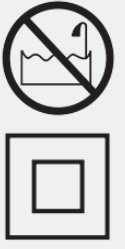

CUIDADO. Não use este aparelho perto de banheiras, duchas, lavatórios ou outros recipientes que contenham água.

APARELHO CLASSE II, proteção contra choque elétrico com proteção adicional de segurança. Isolação dupla.

Na pintura escrita na parte inferior da figura 7, é possível identificar o local de produção do produto, a marca, o modelo como também a tensão, a potência e a frequência do produto, na última linha.

Mesmo localizados na parte inferior do secador, os pictogramas e a pintura escrita são de fácil acesso, e possuem um contraste de cor satisfatória em relação ao objeto, facilitando assim a leitura, considerando o público ao qual este é destinado. No entanto, a falta de pregnância de alguns destes símbolos pode acarretar em utilização incorreta do mesmo, comprometendo a segurança do usuário, uma vez que seu uso doméstico é feito principalmente em ambientes como o banheiro.

\subsubsection{Sistema 3 - Indicador de retirada da tela}

O sistema 3 é constituído pelo indicativo da possível retirada do filtro de ar, através de dois triângulos em baixo relevo (figura 10), para limpeza. Ele possui duas partes na sua composição, a tampa traseira e a tela traseira (itens 5 e 6 - Figura 9). Diferentemente de muitos produtos similares, essa função é uma vantagem, pois permite a sua limpeza, prolongando a vida útil do aparelho. 
Figura 9 - Partes componentes do produto. Fonte: Manual Secador TAIFF GLOSS (2017).

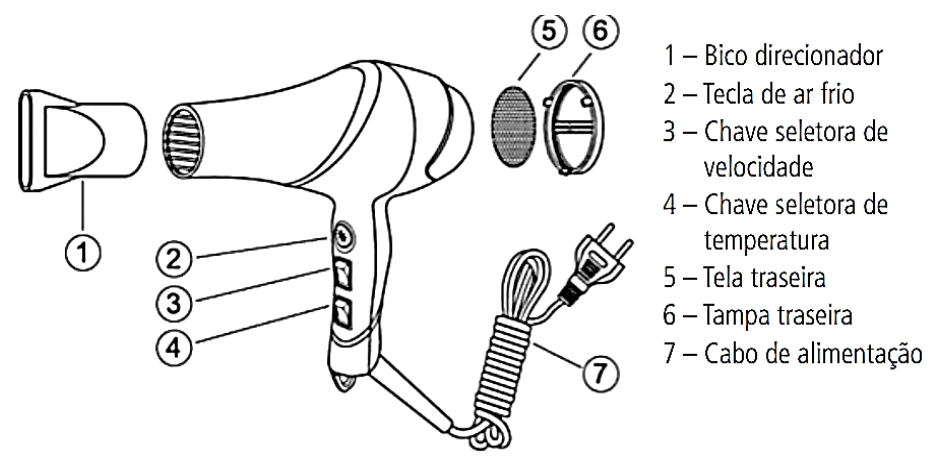

Como ressaltado na figura 10, o filtro possui duas setas de indicações para o lado a ser girado para que possa ser retirado e limpo. No entanto, essas setas não possuem um caráter pregnante quanto aos usuários, muito menos alguma forma de contraste para seu reconhecimento.

Para Dul e Weerdmeester (2004), "o contraste é a diferença de brilho entre a figura e o fundo. Aumentando-se o contraste, há uma melhoria da legibilidade. 0 contraste apresenta diferença maior que a iluminação para a legibilidade".

Essa situação faz com que muitos nem tenham conhecimento do mesmo, a ponto até de confundi-lo com alguma decoração, o que pode diminuir o ciclo de vida do produto em razão da sujeira que se acumula com o passar do tempo.

Fiqura 10 - Tela do filtro de ar. Fonte: Elaborado pelo autor, com base na pesquisa realizada (2017).

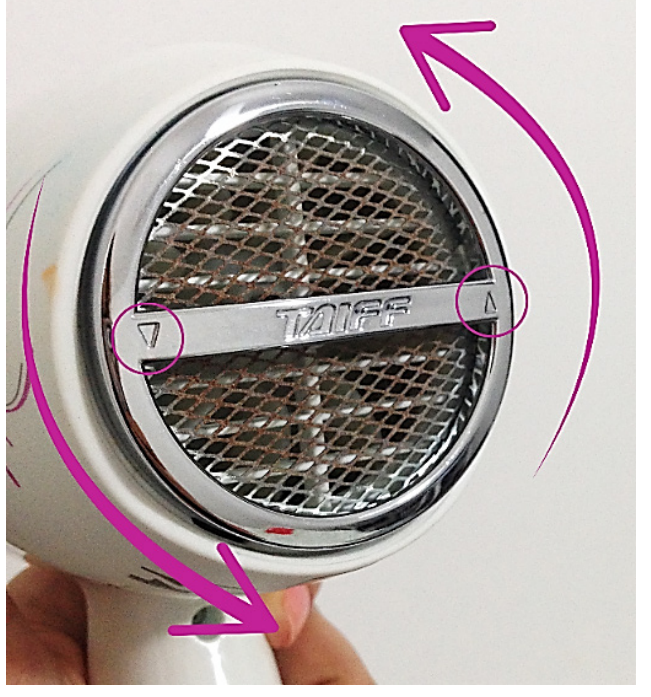

\subsection{Sistema 4 - Ruídos}

Quanto ao sistema informacional auditivo, é possível perceber que assim que se liga o secador ele emite um ruído, indicando funcionamento, junto à saída de ar pela sua frente. Ao acionar as diferentes velocidades com o botão 2 é possível observar que o ruído fica mais intenso (posição II), ou mais ameno (posição I).

\subsection{Sistema 5 - Sensação tátil}

Já em relação à sensação tátil, ela pode ser sentida através da mudança de temperatura referente à troca de posição da chave do botão 3, ficando mais intensa quando está na posição II e abrandando na posição I. 


\section{CONCLUSÃO}

É por meio da relação entre o sistema de informação e homem que se encontra a necessidade de absorção prática e rápida do usuário diante ao produto. Muitos atualmente não dedicam parte do tempo a leitura de manuais, nestes ficam descritos todos os sistemas ali inseridos, porém a motivação intrínseca do ser humano em realizar atividades atrás de seu conhecimento leva as pessoas a entenderem melhor um sistema a qual já possuem repertório.

No produto estudado anteriormente, os sistemas examinados apresentam empecilhos de entendimento, sendo necessário que o usuário recorra ao manual, o que muitas vezes não acontece, pondo em risco sua segurança, diminuindo a vida útil do produto, ou acarretando um baixo nível de satisfação dos usuários.

No caso do botão 1, do sistema 1, o pictograma, formato e cores adotados são positivos, ao serem descrimináveis e facilmente entendidos, atingindo um bom nível de eficiência. 0 que compromete a sua usabilidade, ao diminuir a satisfação do usuário, é o esforço que ele precisa depositar no seu acionamento. Ainda no sistema 1, os botões 2 e 3 são praticamente indistinguíveis, causando uma confusão no usuário, uma vez que o botão 2 além de regular a velocidade também é responsável por ligar/desligar o produto.

Já o sistema 2, de extrema responsabilidade, adota pictogramas que, nesse caso, podem ter significado não tão claro quanto o empregado no sistema 1. Referente ao sistema 3, é preciso uma forma que torne possível o seu reconhecimento, destacando uma função que seria um diferencial do produto. Os sistemas 4 e 5 não apresentam queixas por parte dos usuários ou comprometem o uso do aparelho, atingindo portanto as funções as quais se comprometem com eficácia, garantindo a usabilidade.

A partir das dificuldades constadas, foi possível construir um quadro com diretrizes para a melhoria dos sistemas existentes, como segue.

Quadro 1 - Diretrizes para melhoria dos sistemas do secador TAIFF Gloss. Elaborado pelos autores, com base na pesquisa realizada (2017).

\begin{tabular}{|c|c|c|c|}
\hline Sistema & Componentes & Dificuldades & Propostas \\
\hline \multirow[t]{2}{*}{ Sistema 1} & Botão 1 - Jato Frio & $\begin{array}{l}\text { Exercer constante pres- } \\
\text { são com dedo }\end{array}$ & $\begin{array}{l}\text { Botão com acionamento } \\
\text { único (o acompanhamen- } \\
\text { to da função se daria pelo } \\
\text { sistema de informação } \\
\text { tátil) }\end{array}$ \\
\hline & $\begin{array}{l}\text { Botões } 2 \text { e } 3 \text { - Velocida- } \\
\text { de/ligar/desligar e tem- } \\
\text { peratura }\end{array}$ & $\begin{array}{l}\text { Distinguir os botões entre } \\
\text { si para ligar o aparelho }\end{array}$ & $\begin{array}{l}\text { Adotar um sistema au- } \\
\text { xiliar, como uma pintura } \\
\text { escrita, indicando para } \\
\text { quêcada botão serve; ou, } \\
\text { Adotar pictogramas au- } \\
\text { xiliares como indicativo } \\
\text { das funções (velocidade, } \\
\text { ligar, temperatura); ou, } \\
\text { Adicionar um terceiro } \\
\text { botão, separando as fun- } \\
\text { ções exercidas pelo bo- } \\
\text { tão } 2 \text {. }\end{array}$ \\
\hline
\end{tabular}




\begin{tabular}{|l|l|l|l|}
\hline Sistema 2 & Pictogramas & $\begin{array}{l}\text { Interpretar os significa- } \\
\text { dos }\end{array}$ & $\begin{array}{l}\text { Adicionar cor azul ao } \\
\text { pictograma, facilitando } \\
\text { a compreensão de que é } \\
\text { proibido entrar em con- } \\
\text { tato com água; } \\
\text { Adicionar texto com os } \\
\text { significados ou solicitan- } \\
\text { do a leitura do manual; }\end{array}$ \\
\hline Sistema 3 & Indicador em baixo relevo & Identifica-lo & $\begin{array}{l}\text { Aumentar a forma e adi- } \\
\text { cionar elementos que } \\
\text { configurem a ideia de } \\
\text { seta e giro; ou, } \\
\text { Adicionar texto nas late- } \\
\text { rais indicando que é gira- } \\
\text { tório, removível; ou, } \\
\text { Adotar cor que contraste } \\
\text { com o acabamento pra- } \\
\text { teado. }\end{array}$ \\
\hline
\end{tabular}

Assim, com algumas mudanças nesses sistemas como a utilização do jato frio apenas pelo apertar do botão e não necessitando a manutenção da pressão com o dedo no mesmo, a forma de indicação nos botões de velocidade através dos pictogramas e também o símbolo de indicação do sentido de abertura do filtro para limpeza, trariam ao produto maior vida útil e uma melhor relação entre o usuário e o objeto, resultando na usabilidade, o que garante uma experiência satisfatória, segura e ergonômica para o público.

\section{REFERÊNCIAS}

Associação Brasileira de Ergonomia. O que é Ergonomia? Disponível em: < http://www. abergo.org.br/internas.php?pg=o_que_e_ergonomia>. Acesso em 05 de out. 2017.

Associação Brasileira de Normas Técnicas. NBR 9241-11: Requisitos Ergonômicos para Trabalho de Escritórios com Computadores. Parte 11 - Orientações sobre Usabilidade.. Rio de Janeiro, 2002. 2004.

DUL, Jan; WEERDMEESTER, Bernard. Ergonomia Prática. São Paulo: Edgard Blücher,

FERREIRA, Simone Bacellar Leal; LEITE, Julio Cesar Sampaio do Prado. Avaliação da usabilidade em sistemas de informação: o caso do Sistema Submarino. Curitiba: Revista de Administração Contemporânea, 2003. Disponível em: <http://www.scielo.br/scielo. php?script=sci_arttext\&pid=51415-65552003000200007>. Acesso em 12 set. 2017.

GOMES FILHO, João. Design do Objeto: Design do Produto/Design Gráfico/Design de Moda/Design de Ambientes/Design Conceitual. São Paulo: Escrituras, 2006.

GOMES FILHO, João. Gestalt do Objeto: Sistema de Leitura Visual da Forma. São Paulo: Escrituras, 2004.

IIDA, Itiro. Ergonomia: Projeto e Produção. São Paulo: Edgard Blücher, 2005.

Manual de Instruções do secador TAIFF GLOSS. Disponível em: <http://img.submarino. com.br/manuais/113064431.pdf>. Acesso em 18 set. 2017.

SHIFFMAN, Harvey. Sensação e Percepção. São Paulo: LTC, 2005. 


\section{Sobre os autores}

Layanna Roberta Madeiro Lobo de Castro (Graduanda), UFAL <laycastro17@gmail.com> Thallysson Henrique de Melo Oliveira (Graduando), UFAL <thmello96国gmail.com>

Maria Eduarda Ramos Cavalcanti Rosa (Mestre), UFAL <dudah.cavalcanti@gmail.com> 